\title{
My Experience with this Deadly Situation
}

\section{Conceptual Paper}

Kind of strange that I can remember my first attack like it was five minutes ago and it was and still is on a pain level far beyond anything I have ever felt before or since other than a cluster headache attack...

I was watching TV in my parents living room on the floor with a big pillow when it hit me so hard and so fast, out of nowhere like a ton of bricks. Such incredibly violent and intense pain that I was certain I was dying and had ruptured a blood vessel in my brain or somehow I had been shot in the head and was bleeding out in my brain but wasn't dying. I was waiting to die just knowing it was happening.

I was screaming and crying for help and my parents at first thought I was faking for some reason but soon realized I was in real trouble. I was absolutely scared out of my mind! I still think often of how powerful and literal these attacks are and still wonder how that much pain isn't causing some severe and radical damage. So scary and being so young I have been just certain it caused severe damage and something was terribly wrong. My parents rushed me to the hospital and of course all the tests they did were negative.

I had no idea then that I was destined to live with these terrifying attacks almost every day for the next 40 years. I have been chronic since that first attack, then I had a three year remission in 1979 and it lasted till 1982 then back to being chronic again. However, I also did have three years of 6-7 month cycles. Doctors and Neurologists had no idea that it was Cluster Headaches that I was having back in the early 70's. I was actually told I had some form of "Super Migraines" for that whole first year then it was some rare form of migraine.

I was very naive and ignorant but I found so was everyone else and they really had no idea what I had for certain. My father is a retired dentist and he tried several times to stop my attacks, even using oxygen during an attack while in his chair at his office. His 02 regulator did not go high enough though to be effective. He also tried Novocaine injections around my eye brow and those muscles just above my right ear that swell and become very painful during an attack. Unfortunately, his efforts were unsuccessful.

I never even heard the words cluster headaches until 1991 after diagnosing myself and telling my doctor then seeing the expression on his face when he realized I was right. I tried so Many medications and all seemed to make them worse or just never worked which is a common story with this disorder. No medication has ever been created for $\mathrm{CH}$ and some of the off label medications used to treat it are so powerful and such extreme side effects that they can disable you.

I just got to the point early on because no one could give me a proper diagnoses after almost two years of many doctors and tests and medications that didn't work that I just realized that I

Conceptual Paper
Special Issue - 2016
John Fletcher*
President/Founder, Cluster Headache Foundation Inc., USA
*Corresponding author: John Fletcher, President/
Founder Cluster Headache Foundation Inc., USA, Email:
clusterheadaches@yahoo.com
Received: December 18, 2015 | Published: April 06, 2016

was either going to have to live with these things or not. By no means has it been easy, in fact, it is an hourly battle between severe depression, PTSD and attacks for as long as I can remember.

I grew up being on the ocean and had a successful career as a commercial fisherman, commercial diver, and a 100 ton master of oceans captain for over 30 years, a pilot boat captain, research vessel captain, sport fishing charter boat captain, tuna fishermen, commercial diver among other jobs. I went around 27 years without seeing another doctor and no medication.

I used to use niacin because $200 \mathrm{mg}$ would give the "Flush" and burning feeling all over my body that sometimes it would disrupt an attack is as best I can describe it in about 15 to 30 minutes but also was something I should have not used and probably made them worse as well. Extra strength excedrin was another that I used to the point of getting serious rebounds or medication overuse headaches or other NSAIDS used caused the same thing. It was a vicious cycle and being alone and no medicine that worked put me in a bad situation for many years also still thinking I had "Super Migraines" for 18 years.

Imagine having one of these attacks while diving over 100 feet down. I was also a tuna fisherman for 17 years, imagine lift poling 200 pound tuna having 3 guys hooked up to one leader throwing these giant tuna over our shoulders. There was no way for me to stop and deal with the attack or do anything but bare the attacks while in the middle of critical jobs so I had to get used to others seeing me have attacks and they were always caring and helpful. It was a brutal and hard thing to do trying to maintain and work during an attack and do this kind of job with the pain only another sufferer can know. Water pours out of my eye, sinus swelled shut and on fire and that knife or hot poker in my eye. Working during full $\mathrm{CH}$ attacks with no abortive treatment... Crazy.

That was very hard to do, but I got used to doing it every day and night for over 35 years being at sea. I think working on and under the ocean saved my life in a big way by making me cope with this kind of incredible pain. I was at sea on an average of 300 days a year and it wasn't like I could just take a bus ride home. That and the support and caring of my fellow crew members saved me and was the only career that would have worked for me personally to make it so many years without medical help. 
In 1991 I diagnosed myself after reading a great deal about all the different primary and secondary headaches and $\mathrm{CH}$ was spot on down the line with all the classic symptoms of watery eye, extreme pain in my right eye, drooping eyelid, plugged up sinus on right side and 3 to 12 attacks daily lasting usually 20 to 30 minutes but sometimes over two hours almost every day year round with very few days of relief a year if any.

When I get an attack I feel the pain in my eye grow, then my heart starts to flip flop for a couple of minutes as the attack hits and as the anxiety goes through the roof in anticipation the pain grows rapidly in and around my eye and side of my head, neck and shoulders get stiff as rocks and very painful, my right eye starts to water profusely, my right sinus swells shut and is very painful, the muscles above and around my right ear, temple and over my eyebrow swells and my eyelid droops.

Then the literal feeling of a knife or screwdriver, a hot poker, all are what it feels like violently being pounded into my eye with a hammer and pounded in and out of my right eye through the side of my temple with extreme force and my eye literally feels like it will explode is as best I can describe them and this goes from no pain at all into this in just minutes. Rolling on the floor, pulling out my hair, punching my head, smashing my head into the wall, screaming and crying, are the symptoms of a bad attack.

It is the literal, physical feeling of that knife in my eye being pounded in and out, over and over from 3 to 12 or more times a day every day and night year round. I was diagnosed several times since then by neurologists stating that I had chronic cluster headaches. I have had many serious injuries in my life, 17 major operations most all life saving stemming from perforated diverticulitis (hole in my intestine) and severe peritonitis.

I have severe nerve damage from all those operations which ended my career and permanently disabled me. I have had broken arms, hands, feet, leg, ribs, sternum, collar bone etc. Two heart attacks, C.o.p.d, severe burns, lacerations to the bone, spinal taps, kidney stones, bleeding ulcer, massive infections, peritonitis etc. (I was in a few car accidents) Being a commercial fisherman all my life with cluster headaches, I know pain and endless hours of back breaking work but the only reason I even mentioned these things at all is because none of these events came even close to the intensity of the pain of a bad cluster attack, none of it.

These are called suicide headaches for a reason. Incredibly severe depression has followed me for so long that I lost the feeling of being normal many years ago. Just having attacks every day with no end in sight had me very depressed most of the time. PTSD is something new also been associated with $\mathrm{CH}$ and I have no doubt it is true. Most every attack is a very traumatic experience loaded with anxiety and just plain terrifying, anxiety filled fear of getting another "CH-10". These attacks are so far off a normal pain chart that they even came up with a $\mathrm{CH}$ pain scale called the "KIP Scale" which is in the directory of the CHF website.

I have had periods of months where I was so terrified to lay down and sleep because of having periods of beyond brutal attacks and some attacks that just scared the tar out of me they were so powerful. I always have had more nocturnal attacks as soon as I hit REM sleep and the night attacks always seem to be the worst. The fear of the "next one" actually caused me to go six weeks straight without laying down and ended up in the hospital for a week from severe sleep deprivation and had gained so much fluid it was in my lungs and around my heart sack.

My legs and body were so swollen you could push your finger into my skin on my legs and arms and the imprint of your finger would stay in an inch or so. I was on $1200 \mathrm{mg}$ of Depakote and $400 \mathrm{mg}$ of Topamax when I finally gave up on traditional medications. I was so messed up from the side effects I couldn't drive a car or speak clearly or even walk without staggering. Slurring my words and numb in all my extremities also having many very powerful attacks that my oxygen would not touch in most cases. I had actually passed out on some attacks from the incredibly powerful intensity. Neither medication could stop my attacks and made them so much worse. I was truly at my end... Again.

In December of 2011 I finally went online to find out about cluster headaches and what I could do to stop the pain. Up until this point I had rarely ever used a computer and really did not know how to use it very well. I found some great support groups that I didn't know existed and were very knowledgeable on $\mathrm{CH}$ and such incredible support and wonderful caring and helpful "family" no longer being alone was very profound. I found a vitamin regimen called the Vitamin D3 Anti-Inflammatory regimen when I met Pete Batcheller on $\mathrm{CH}$ dot com that stopped my attacks in three days after almost 40 years of being chronic and was the first treatment to ever work for me but it eventually wore off after a year and a half and I was back to being chronic again.

The preventative Vitamin D3 anti-inflammatory regimen created by Pete Batcheller is pretty famous among CHers on $\mathrm{CH}$ dot com and another wonderful treatment that needs more study and at over an $80 \%$ success rate. Without high flow oxygen I don't think I would have made it this far as it is the best abortive treatment we have and safest. One thing I and every other CHer runs into is we are still made to wait sometimes hours in the ER before given any help when all that has to be done in most cases is be given high flow oxygen at 15 to $25 \mathrm{Lpm}$ or higher that can stop an attack in 3 to 5 minutes.

The protocol needs to be changed and as soon as we enter the ER and say cluster headache a bottle of oxygen needs to be given to us. Being a CCHer I tried very hard to never go to the hospital because of the stigma of the word" Headache". It is a powerful stigma, in some cases so little has been taught to our doctors that some think we are drug seekers which is a story I hear frequently. That I will say is the farthest thing from the truth and is so demeaning and hurtful let alone embarrassing that I don't ever want to go to a hospital for $\mathrm{CH}$ ever, period. If a cluster headache patient goes to an ER it is because the pain has become to unbearable and for no other reason. Having to go through being accused of drug seeking when your fighting severe pain and depression and hurtful words are intensified ten fold. It can add to the name suicide headaches...

I had been reading about "Busting" from www.clusterbusters. org website for a few years and had always been very curious about it as the success rates for stopping the pain are astronomical at close to $90 \%$ and I had always thought that would be my next attempt at a preventative treatment to stop the pain. 
Treating cluster headaches with tryptamines as a preventative treatment is proving to be the most consistently effective alternative treatment or any treatment, surgery or procedure for that matter known and is being advocated at the annual "Headache on the Hill" in Washington DC.

ClusterBusters.org patient advocates and some of the most respected neurologists in the world are also advocating for funds to research new and promising alternative treatments for cluster and primary headaches such as hallucinogens, vitamin D3 and others as well as traditional medications and treatments. I started the treatments on January 1st, 2014 and used Psilocybin mushrooms. I studied carefully and learned how it was done, then I went completely cluster headache free again for eight months and then they came back just recently. I used three low doses of psilocybin and am cluster headache free again to date. I recently joined the new tryptamine $5 \mathrm{MeO}$ DALT case study and am $\mathrm{CCH}$ free for almost eight months now.

This is only the third treatment in 42 years that has helped me and only the third to get me to a complete cluster headache remission. I also attribute that three year remission back in 1979 through 1982 to psilocybin as that was the first time in my life I tried it and I was 19 years old in 1979 and experimenting with recreational use of psilocybin when it stopped my headaches but I didn't realize it was the psilocybin that caused it to happen. Had I known.... I have no wish to trip and you don't need a recreational dose for this treatment to work so for me, this is pure relief, just pure relief of such intense deep to the core, pure anguish and the feeling of the weight of the world coming off my shoulders.

Being mostly $\mathrm{CH}$ free has completely changed my life. I have devoted my life to helping other sufferers and trying to make a difference with this horrific disorder. I am one of three administrators for the $5000+$ member cluster headache patient support group ("Cluster Headaches") the largest of its kind in the world and I counsel and help folks who are struggling on a daily basis. I designed our first accepted awareness ribbon and created the Cluster Headache Foundation website in May 2012 to help all who needed to know and understand cluster headaches. I incorporated the Cluster Headache Foundation as a non-profit charitable organization in June 2015. I have studied cluster headaches every day 15 hours a day since the end of 2011 and I'm still learning, but I learned enough to help others and make a difference.

I keep reading and seeing so many great success stories of folks that have used one of the different "Busting" methods and now
I am one of those success stories... To learn more about busting (Tryptamines) for cluster headaches and to bring yourself up to date with headache advocacy please see www.clusterbusters.org.

I realize this way of treatment is controversial, but when you're talking about pain so powerful you want to die and the reason they are called suicide headaches. The sheer desperation to escape the constant terror of another bad attack and the fact that for many there is no medication to help from the medical community. I personally think because of the severity of this disorder getting relief from anything that has safely proven to work legal or not is justifiable as in so many cases the option is suicide.

Another tryptamine called 5-MeO-Dalt has recently come forward. Over two hundred $\mathrm{CH}$ patients have tried it and about 50 involved in the case study, it has been very effective to this point and remission rates are very high $87 \%$ which makes this one of the two best treatments ever found for $\mathrm{CH}$. It's showing again how effective tryptamines are at stopping $\mathrm{CH}$ both $\mathrm{CCH}$ and ECH (Episodic Cluster Headaches). This is one of the reasons I wrote my story is because bottom line, Tryptamines work and we desperately need more research to understand why they are so effective at stopping cluster headaches.

We need to get serious and follow this research to its end, which in my and many others opinions may lead us or possibly play a part to get us to a cure. This is considered to be "The most painful condition known to medical science" Quoted by Professor of Neurology. Peter Goadsby of UCSF and Kings College in the U.K. A world leader in headache disorder research and an acquaintance of mine. It needs the attention it deserves and is not getting.

Cluster Headaches are very close to the same prevalence as multiple sclerosis at $0.1 \%$ of the population. We need the help, research and attention the most painful condition known to be pushed up to the forefront of scientific research and start on a positive path to understanding cluster headaches and ending the pain and suffering for millions.

Thank you for reading my story, obviously there is a lot more to this. This war can be won, determination \& perseverance is a huge factor. Having purpose and working, staying busy and making sure the oxygen bottle is always close, having a support dog has helped me greatly too. This covers the basics of my 42 years of chronic cluster headaches. I sincerely hope it may help in some way. Please watch the following video as it may help even better to understand the severity of this disease. 